\section{Cureus}

\title{
Pattern of Local Recurrence and Distant Metastasis in Breast Cancer By Molecular Subtype
}

Xingrao Wu ${ }^{1}$, Ayesha Baig ${ }^{2}$, Goulnar Kasymjanova ${ }^{3}$, Kamran Kafi ${ }^{2}$, Christina Holcroft ${ }^{4}$, Hind Mekouar ${ }^{2}$, Annie Carbonneau ${ }^{2}$, Boris Bahoric ${ }^{2}$, Khalil Sultanem ${ }^{2}$, Thierry Muanza ${ }^{2}$

1. Department of Radiation Oncology, KunMing Medical University Yunnan Provincial Cancer Hospital, Kunming, People's Republic of China 2. Department of oncology, Division of radiation oncology, Segal Cancer Center-Jewish General Hospital, McGill University, Montréal, Canada 3. Department of Medicine and Pulmonary Oncology, Jewish General Hospital, McGill University, Montréal, Canada 4. Statistical Consultation Service Centre for Clinical Epidemiology, Jewish General Hospital, McGill University, Montréal, Canada

$\square$ Corresponding author: Thierry Muanza, tmuanza@yahoo.com Disclosures can be found in Additional Information at the end of the article

\section{Abstract}

Background and Purpose: No longer considered a single disease entity, breast cancer is being classified into several distinct molecular subtypes based on gene expression profiling. These subtypes appear to carry prognostic implications and have the potential to be incorporated into treatment decisions. In this study, we evaluated patterns of local recurrence (LR), distant metastasis (DM), and association of survival with molecular subtype in breast cancer patients in the post-adjuvant radiotherapy setting.

Material and Methods: The medical records of 1,088 consecutive, non-metastatic breast cancer patients treated at a single institution between 2004 and 2012 were reviewed.

Estrogen/progesterone receptors (ER/PR) and human epidermal growth factor receptor-2 (HER2) enrichment were evaluated by immunohistochemistry. Patients were categorized into one of four subtypes: luminal-A (LA; ER/PR+, HER2-, Grade 1-2), luminal-B (LB; ER/PR+, HER2-, Grade > 2), HER2 over-expression (HER2; ER/PR-, HER2+), and triple negative (TN; ER/PR-, HER2-).

Results: The median follow-up time was 6.9 years. During the follow-up, $16 \%(174 / 1,088)$ of patients failed initial treatment and developed either LR (48) or DM (126). The prevalence of LR was the highest in TN (12\%) and the lowest in LA (2\%). Breast or chest wall relapse was the most frequent site $(\approx 80 \%)$ of recurrence in LA, LB, and HER2 subtypes, whereas the regional lymph nodes and chest wall were the common sites of relapse in the TN group (50.0\%). DM rates were 6.4\% in LA, $12.1 \%$ in LB, $19.2 \%$ in HER2, and $27.4 \%$ in TN subgroups. Five-year survival rates were $84 \%, 83 \%, 84 \%$, and $77 \%$ in the LA, LB, HER2 and TN subgroups, respectively. There was a statistically significant association between survival and molecular subtypes in an univariate analysis. In the adjusted multivariate analysis, the following variables were independent prognostic factors for survival: T stage, $\mathrm{N}$ stage, and molecular subtype.

Wu et al. This is an open access article distributed under the terms of the Creative Commons Attribution License CC-BY 3.0., which permits unrestricted use, distribution, and reproduction in any medium, provided the original author and source are credited.
Received 09/06/2016 Review began 09/12/2016 Review ended 12/09/2016 Published 12/09/2016

source are credited.
Conclusions: Of the four subtypes, the LA subtype tends to have the best prognosis, fairly high survival, and low recurrent or metastases rates. The TN and HER2 subtypes of breast cancer were associated with significantly poorer overall survival and prone to earlier recurrence and metastases. Our results demonstrate a significant association between molecular subtype and survival. The risk of death and relapse/metastases increases fewfold in TN compared to LA. Future prospective studies are warranted and could ultimately lead to the tailoring of adjuvant 
radiotherapy treatment fields based on both molecular subtype and the more conventional clinicopathologic characteristics.

Categories: Radiation Oncology

Keywords: breast cancer, molecular subtype, pattern, recurrence

\section{Introduction}

Breast cancer $(\mathrm{BC})$ is a heterogeneous disease with widely varying clinical behaviors and treatment responses, despite similarities in standard clinicopathologic characteristics, such as the histological type, tumour size, lymph node status, lymphovascular space invasion, and grade. This diversity in natural history may reflect the underlying molecular biology of the disease. Four major molecular subtypes of BC have been elucidated through gene expression profiling and include luminal-A (LA), luminal-B (LB), human epidermal growth factor receptor2-enriched (HER2), and basal subtypes [1-3]. Because gene expression profiling is resource intensive and not currently feasible for routine use, BC molecular subtypes can be approximated by standard immunohistochemical features with the LA subtype representing hormone receptor-positive tumours with low proliferative activity, the LB subtype representing hormone receptor-positive tumours with high proliferative activity, the HER2 subtype representing HER2+ tumours, and the basal subtype representing triple negative (TN) disease with no expression of hormone receptors or HER2 [4].

Molecular subtypes in BC have been correlated with differences in recurrence rates and survival. Typically, LA subtypes have the most favourable outcomes and TN subtypes experience higher rates of locoregional recurrence and DM, as well as lower survival rates. Controversies with regard to the optimal locoregional management of BC exist, and molecular subtypes are being increasingly considered for prognostication and therapy decisions [1, 45]. With the prognostic information garnered from molecular subtype analyses, there is potential to further refine and personalize treatment for BC patients. A key component in tailoring treatment based on molecular subtype is the better understanding of their patterns of local, regional, and distant recurrence.

This study evaluated the pattern of recurrence and disease-free and overall survival by molecular subtype in patients with newly diagnosed BC patients treated with either breastconserving therapy or mastectomy and adjuvant radiotherapy.

\section{Materials And Methods}

\section{Patients}

The medical records of female histologically-confirmed breast cancer patients treated with radiation therapy at the Jewish General Hospital between 2004 and 2012 were retrospectively reviewed. Stage 4 patients were excluded. All patients underwent nodal staging and received external beam radiotherapy (EBRT) with a dose of 42-50 Gy in 16-25 fractions. In addition, patients aged 60 years or younger and/or patients with positive surgical margins or margins less than $2 \mathrm{~mm}$ were prescribed a boost, consisting of an additional 10-15 Gy in four to six fractions, to the tumor bed. Clinicopathologic and treatment information were collected and included age, stage, histology, margin status ( $<3 \mathrm{~mm}$ vs. $\geqslant 3 \mathrm{~mm})$, and radiotherapy and systemic treatment details.

The Jewish General Hospital Ethics Review Board approved this retrospective study (approval \# CR1366). Informed patient consent was obtained at the time of treatment. 


\section{Molecular subtype categorization}

Molecular subtypes were approximated using hormone receptor status, HER-2 status, and histologic grade. Patients were categorized into four subtype groups: LA (ER/PR+, HER2-, Grade 1-2) LB (ER/PR+, HER2-, Grade > 2); HER2+ (ER/PR+ or ER/PR-, HER-2+); and TN (ER/PR, HER2-). ER/PR status was determined on the basis of immunohistochemistry (IHC) staining. Tumours were considered HER2+ if they scored 3+ on IHC or if they were 2+ on IHC and demonstrated HER2 amplification on fluorescence in situ hybridization (FISH) [4]. The histologic grade was used as an approximation of the tumour proliferation marker Ki67 [6].

\section{Follow-up and study end points}

Follow-up started on the day of pathology-proven diagnosis and ended on the date the patient was last observed or the date of death. The database was frozen for the statistical analyses on October 2014. Patients who were alive at end of the study or lost to follow-up were censored. One thousand and eighty-eight out of 1,189 patients were included in this analysis. The two primary variables of interest were locoregional recurrence (LRR) and distance metastasis (DM). Patterns of LRR were evaluated and were categorized as local breast/chest wall recurrence and regional lymph node recurrence (axillary, supraclavicular, internal mammary, contralateral). DM was categorized as lung, liver, brain, and bone. Study end points were defined as:

- Overall survival (OS) was defined as the time from the diagnosis to death from any cause

- Progression-free survival (PFS) was defined as the time from the diagnosis to recurrence and/or metastasis, whichever is the earliest.

- Local recurrence-free survival (LRFS) defined as a time elapse between diagnosis and recurrence or death dates

- Distant metastasis-free survival (DMFS) is defined as a time elapsed between diagnosis and metastasis or death dates.

\section{Statistics}

The demographic and clinical characteristics of patients in different molecular subtypes were first examined using Pearson c2 tests for categorical variables and ANOVA test for continuous variables. The Kaplan-Meier analysis was used for OS, LRFS, and DMFS with a log-rank test to assess the significance of molecular subtypes for those three outcome variables. The effect of significant clinicodemographic variables on the outcome (OS) was analyzed in univariate Cox regression analysis. The variables assessed in the univariate analysis were age, menopausal status, stage (T\&N), tumor grade, histology, chemotherapy, radiation therapy (RT) boost, and molecular subtypes. In the multivariate Cox regression analysis, we adjusted the outcome for the variables that were significant in the univariate analysis: stage $(T \& N)$, chemotherapy, grade, and molecular subtypes. A p-value of $<0.05$ was considered significant. Hazard ratios and 95\% CI were calculated for each variable in the model. All analyses were performed using the Statistical Package for Social Sciences (SPSS) 17.0 (IBM SPSS Statistics, Armonk, NY).

\section{Results}

A cohort of 1,189 consecutive female patients with breast cancer diagnosed between 2004 and 2012 was identified. In all, 101 patients were excluded from the analysis because of missing molecular subtype information. Therefore, 1,088 patients were available for analyses. The minimum follow-up was 10 months with a median follow-up of 6.9 years. During the follow-up, 80 patients died, eight were lost to follow-up, 48 patients relapsed, and 126 developed distant 
metastases. All patients received EBRT \pm boost RT. For systemic treatment, $63 \%$ of patients received cytotoxic chemotherapy, $71.8 \%$ received hormonal therapy, and $12.1 \%$ of received trastuzumab (Table 1).

\begin{tabular}{|c|c|c|c|c|c|c|c|c|c|c|c|}
\hline Covariates & Total & $\%$ & LA & $\%$ & LB & $\%$ & HER2 & $\%$ & TN & $\%$ & $P$ value \\
\hline & $\mathrm{N}=1088$ & $100 \square$ & $\mathrm{N}=644$ & 59 & $\mathrm{~N}=173$ & 16 & $\mathrm{~N}=125$ & 12 & $N=146$ & 13 & \\
\hline Age & & & & & & & & & & & $<0.001$ \\
\hline Mean \pm SD (years) & $59.1 \pm 12$ & & $60.6 \pm 12$ & & $57.4 \pm 13$ & & $57.0 \pm 2$ & & $56.6 \pm 13$ & & \\
\hline Age at diagnosis & & & & & & & & & & & 0.013 \\
\hline$\leq 44$ & 139 & 12.7 & 66 & 10.2 & 28 & 16.2 & 18 & 14 & 27 & 18.5 & \\
\hline$>44$ & 949 & 87.3 & 578 & 89.8 & 145 & 83.8 & 107 & 86 & 119 & 81.5 & \\
\hline Menopausal status & & & & & & & & & & & 0.005 \\
\hline Pre-menopausal & 277 & 25.5 & 139 & 27.6 & 52 & 30.0 & 41 & 33.0 & 45 & 31.0 & \\
\hline Post-menopausal & 809 & 74.5 & 504 & 78.4 & 121 & 70.0 & 83 & 67.0 & 101 & 69.0 & \\
\hline T stage & & & & & & & & & & & $<0.001$ \\
\hline T1 & 625 & 57.4 & 432 & 67.3 & 69 & 39.9 & 61 & 42.8 & 61 & 41.8 & \\
\hline T2 & 361 & 33.2 & 163 & 25.3 & 81 & 46.8 & 53 & 42.4 & 64 & 43.8 & \\
\hline T3 & 62 & 5.7 & 33 & 5.1 & 11 & 6.4 & 5 & 4.0 & 13 & 8.9 & \\
\hline T4 & 40 & 3.7 & 14 & 2.2 & 12 & 6.9 & 6 & 4.8 & 8 & 5.5 & \\
\hline N-stage & & & & & & & & & & & 0.001 \\
\hline No & 750 & 68.9 & 500 & 77.6 & 93 & 53.8 & 63 & 50.4 & 94 & 64.4 & \\
\hline $\mathrm{N} 1$ & 244 & 22.4 & 101 & 15.7 & 60 & 34.7 & 49 & 39.2 & 34 & 23.3 & \\
\hline N2 & 83 & 7.6 & 38 & 5.9 & 18 & 10.4 & 13 & 10.4 & 14 & 9.6 & \\
\hline N3 & 11 & 1.0 & 5 & 0.8 & 2 & 1.2 & 0 & 0 & 4 & 2.7 & \\
\hline TNM Stage & & & & & & & & & & & $<0.001$ \\
\hline 1 & 547 & 50.3 & 393 & 61.0 & 57 & 33.0 & 48 & 38.4 & 49 & 33.5 & \\
\hline II & 399 & 36.7 & 191 & 29.7 & 59 & 49.0 & 59 & 47.2 & 64 & 43.9 & \\
\hline III & 142 & 13.0 & 60 & 9.3 & 18 & 18.0 & 18 & 14.4 & 33 & 22.6 & \\
\hline Tumor grade & & & & & & & & & & & $<0.001$ \\
\hline $1-2$ & 729 & 47.3 & 642 & 100 & 0 & 0 & 54 & 43.2 & 32 & 22.9 & \\
\hline 3 & 355 & 42.7 & 40 & 68.1 & 173 & 100 & 71 & 56.8 & 110 & 77.1 & \\
\hline Histology Type & & & & & & & & & & & $<0.001$ \\
\hline
\end{tabular}




\section{Cureus}

Invasive lobular

Invasive ductal

Mixed $^{1}$

Others $^{2}$

Surgical

Lumpectomy

Mastectomy

Resection margin

Negative

Positive

Margin distance

$\leq 3 \mathrm{~mm}$

$>3 \mathrm{~mm}$

Chemotherapy

Neoadjuvant

Adjuvant

None

Hormonal therapy

Yes

No

Herceptin therapy

Yes

No

Radiation (RT)

Boost $^{3}$

No boost

LR

DM

Death

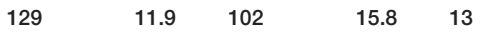

890

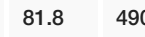

40

107
$3.7 \quad 30$

$2.6 \quad 22$ $\begin{array}{ll}76.0 & 154\end{array}$

$4.7 \quad 4$

$3.5 \quad 2$

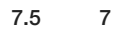

$89.0 \quad 111$

$2.3 \quad 5$

1.22

$\begin{array}{llllllllll}81 & 90.0 & 588 & 91.3 & 148 & 85.5 & 114 & 91.2 & 131 & 89.7\end{array}$

$\begin{array}{llllllllll}1046 & 96.1 & 616 & 95.7 & 167 & 96.5 & 122 & 97.6 & 141 & 96.6\end{array}$

$\begin{array}{lllllllll}42 & 3.9 & 28 & 4.3 & 6 & 3.5 & 3 & 2.4 & 5\end{array}$

0.735

6

$\begin{array}{lll}108 & 9.9 & 44\end{array}$

$578 \quad 53.1 \quad 294$

402 $\begin{array}{ll}6.8 & 17\end{array}$

$45.7 \quad 117$

$47.5 \quad 39$
$9.8 \quad 19$

$67.6 \quad 76$

$22.5 \quad 30$

$<0.001$

$\begin{array}{llllllllll}781 & 71.8 & 554 & 86.0 & 155 & 89.6 & 69 & 55.2 & 3 & 2.1\end{array}$

$\begin{array}{llllllllll}307 & 28.2 & 90 & 14.0 & 18 & 10.4 & 56 & 44.8 & 143 & 97.9\end{array}$

$<0.001$

$\begin{array}{rrrrrrrrrr}140 & 12.9 & 15 & 2.3 & 19 & 89.0 & 104 & 83.2 & 2 & 1.4 \\ 948 & 87.1 & 629 & 97.7 & 154 & 11.0 & 21 & 16.2 & 144 & 98.6\end{array}$

$\begin{array}{llllllllll}948 & 87.1 & 629 & 97.7 & 154 & 11.0 & 21 & 16.2 & 144 & 98.6\end{array}$

$<0.001$

$\begin{array}{llllllllll}533 & 51.0 & 302 & 46.9 & 83 & 48.0 & 65 & 52.0 & 80 & 54.8\end{array}$

$\begin{array}{llllllllll}555 & 49.0 & 342 & 53.1 & 90 & 52.0 & 60 & 48.0 & 66 & 45.2\end{array}$

$\begin{array}{llllll}48 & 4.4 & 13 & 2.0 & 7\end{array}$

$4.0 \quad 10$

$8.0 \quad 18$

$12.0<0.001$

$126 \quad 11.6 \quad 41$

$6.4 \quad 21$

$12.1 \quad 24$

19.240

$27.4<0.001$

$7.4 \quad 25$

$3.9 \quad 11$

$6.4 \quad 12$

$9.7 \quad 32$

$21.9<0.001$

\section{TABLE 1: Clinicopathologic Characteristics of Patients}




\section{Cureus}

1 - Mixed = lobular+ductal, lobular+DCIS, ductal+DCIS

2 - Others = tubular, medullar, and mucinous

3 - Boost $=$ radiation boost to breast surgical cavity

DCIS: ductal carcinoma in situ; DM: distant metastasis; HER2: human epidermal growth factor receptor-2; LA: luminal-A; LB: Iuminal-B; LR: local recurrence; SD: standard deviation; TN: triple negative

The prevalence of different molecular subtypes was: LA - 644 (59\%), LB - 173 (16\%), TN - 146 (13\%), and HER2 - 125 (12\%). Table 1 presents baseline characteristics of molecular subtypes. In our cohort, TN tumors, when compared to other subtypes, occurred more often in younger women, in a more advanced stage, and more often invasive ductal histology with Grade 3 tumor.

Sixteen percent of patients $(174 / 1,088)$ failed initial treatment and developed either recurrence (48) or distal metastasis (126) (Figure 1).

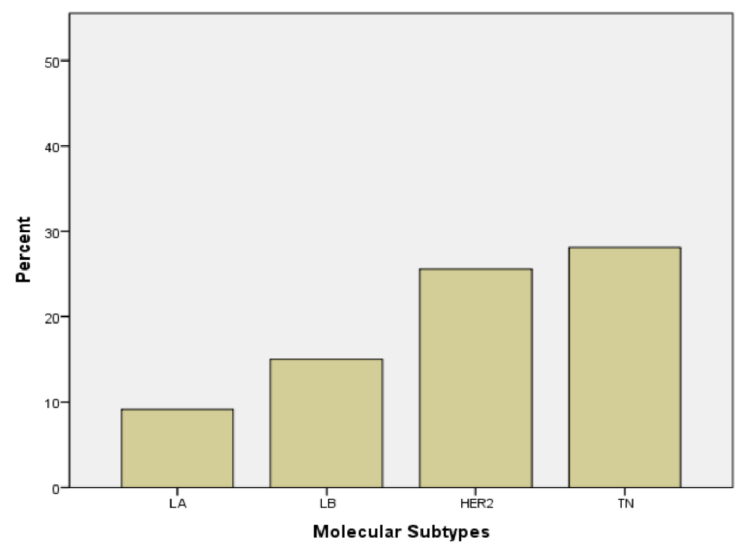

FIGURE 1: Failure Rate (Local Recurrence + Distal Metastases) Among Different Groups of Molecular Subtypes

The failure rate was the highest in TN tumors. Detailed rates of LR and DM are shown in Table 2 . 


\section{Cureus}

\begin{tabular}{|c|c|c|c|c|c|}
\hline \multirow[t]{2}{*}{ Recurrence Pattern } & LA\% & LB\% & HER2\% & TN\% & $P$ value \\
\hline & $N=12$ & $N=6$ & $N=10$ & $N=18$ & \\
\hline Breast & $5(41.7)$ & $2(33.3)$ & $5(50.0)$ & $2(11.1)$ & 0.451 \\
\hline Chest wall & $5(41))$. & $32(50.0)$ & $3(30.0)$ & $7(38.9)$ & \\
\hline Ipsilateral lymph nodes & $1(8.3)$ & $1(16.7)$ & $2(20.0)$ & $8(44.4)$ & \\
\hline Internal mammary nodes & $1(8.3)$ & $0(0.0)$ & $0(0)$ & $1(5.6)$ & \\
\hline Contralateral & 0 & $0(9.0)$ & $0(0)$ & $0(0.0)$ & \\
\hline \multirow[t]{2}{*}{ Metastasis pattern } & LA\% & LB\% & HER2\% & TN\% & $P$ value \\
\hline & $\mathrm{N}=40$ & $N=21$ & $N=25$ & $N=40$ & \\
\hline Bone & $22(55.0)$ & $9(42.9)$ & $9(36.0)$ & $10(25.0)$ & 0.379 \\
\hline Lung & $11(27.5)$ & $8(38.1)$ & $8(32.0)$ & $17(42.5)$ & \\
\hline Brain & $1(2.5)$ & $3(14.3)$ & $5(20.0)$ & $7(17.5)$ & \\
\hline Liver & $4(10.0)$ & $1(4.8)$ & $2(8.0)$ & $3(7.5)$ & \\
\hline Others & $2(5.0)$ & 0 & $1(4.0)$ & $3(7.5)$ & \\
\hline
\end{tabular}

\section{TABLE 2: Recurrence and Distant Metastasis by Molecular Subtypes}

HER2: human epidermal growth factor receptor-2; HR: hazard ratio; LA: luminal-A; LB: luminal-B; TN: triple negative

Of the four subtypes, the highest LR rate was among TN patients - 12\% (18/146), followed by HER2 - 8\% (10/125), then by LB - 4\% (7/173). Luminal A tumors tend to have the lowest LR rate - 2\% (13/644). The most common sites of LR were breast and chest wall (32/48), followed by regional lymph nodes (16/48) for LA, LB, and HER2 with breast and chest wall being about 80\% of recurrence. However, for $\mathrm{TN}$, the rate of recurrence in regional lymph nodes increased up to $50 \%$.

The prevalence of DM was highest among TN - 27.4\% (40/146) as well, followed by HER2 $19.2 \%(24 / 125)$, then by LB - 12.1\% (21/173). LA had the lowest rate of DM - $6.4 \%(41 / 644)(\mathrm{p}<$ 0.001). The most common sites of DM were bone (39\%) and lung (35\%) for all four subtypes (Table 2). Prevalence of brain, liver, and pelvis metastasis was higher in TN and HER2 groups when compared to LA and LB (Table 2).

Five-year survival rates were $84 \%$ for LA, $83 \%$ for LB, $84 \%$ for TN, and $77 \%$ for HER2 subtypes. There was a statistically significant association between survival and molecular subtypes in an unadjusted analysis (Figures 2-5). 


\section{Cureus}

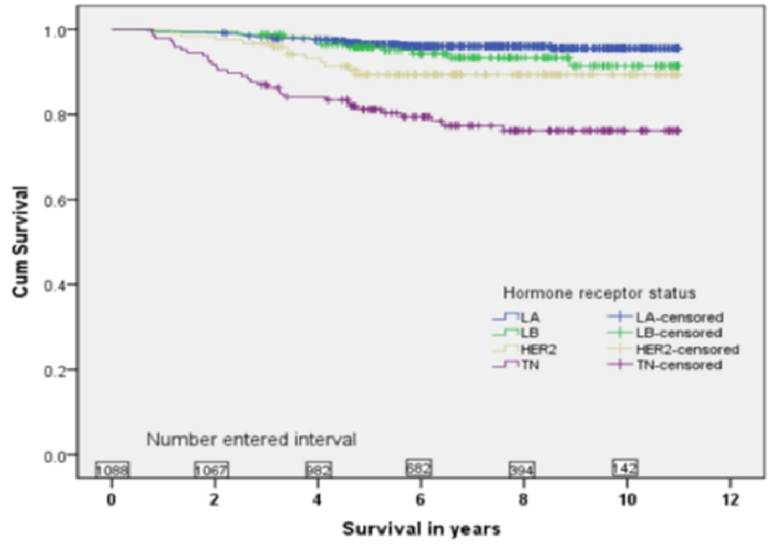

FIGURE 2: Overall Survival by Molecular Subtypes $(p<0.001)$

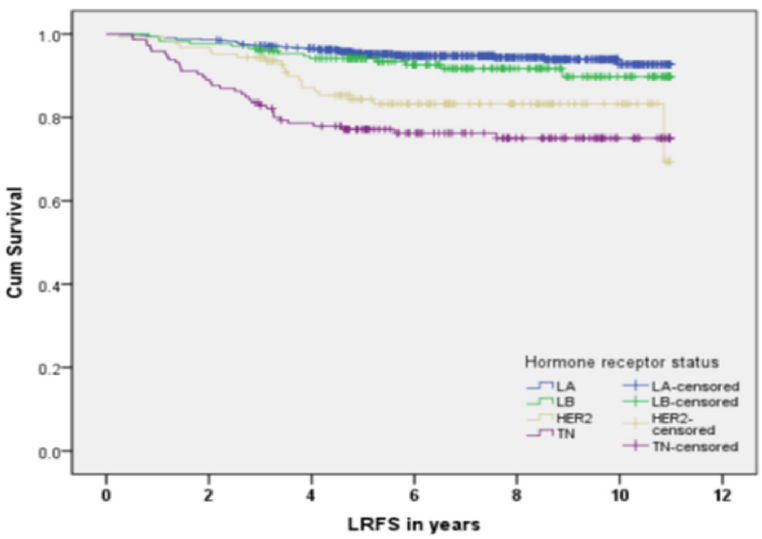

FIGURE 3: Local Recurrence-Free Survival by Subtypes $(p<$ 0.001)

LRFS $=$ local recurrence-free survival 


\section{Cureus}

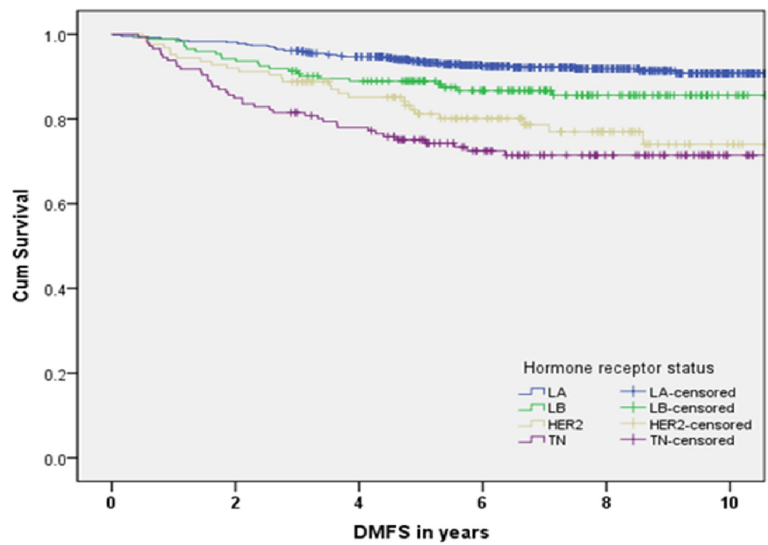

FIGURE 4: Distant Metastasis-Free Survival by Molecular Subtypes $(p<0.001)$

DMFS = distant metastasis-free survival

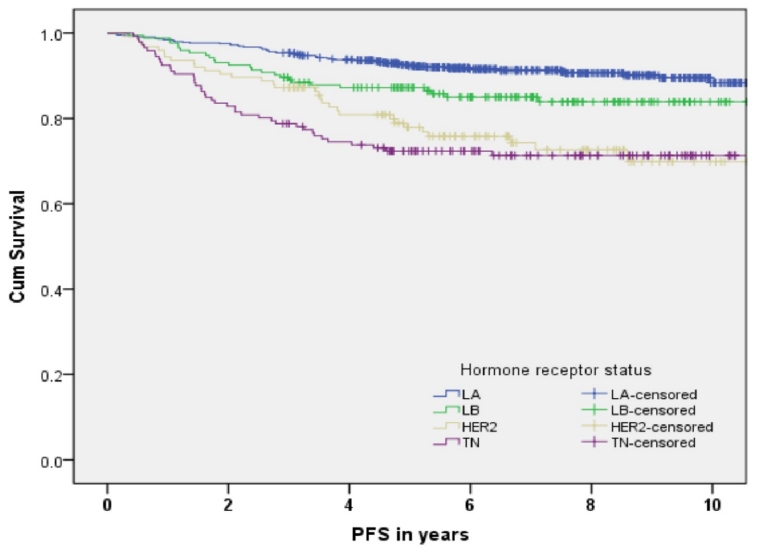

FIGURE 5: Progression-Free Survival by Molecular Subtypes ( $p$ $<0.001$ )

PFS $=$ progression-free survival

The medians for OS, PFS, LRFS, and DMFS were not reached. However, in all four endpoints, the survival was significantly shorter for TN compared to LA and LB subtypes $(p<0.001)$. Furthermore, the LA subtype had the best survival outcome in all endpoints $(p<0.001)$. In the 


\section{Cureus}

adjusted multivariate analysis, the following variables were independent prognostic factors for survival: T stage, $\mathrm{N}$ stage, and molecular subtype (Table 3).

\begin{tabular}{|c|c|c|c|c|c|c|c|c|c|c|}
\hline \multirow[b]{2}{*}{ Covariates } & \multicolumn{3}{|l|}{ os } & \multicolumn{4}{|l|}{ LRFS } & \multicolumn{3}{|l|}{ DMFS } \\
\hline & $\begin{array}{l}\text { Hazard } \\
\text { ratio }\end{array}$ & $95 \% \mathrm{Cl}$ & $\begin{array}{l}\text { P- } \\
\text { value }\end{array}$ & HR & \multicolumn{2}{|c|}{$95 \% \mathrm{Cl}$} & $\begin{array}{l}\mathrm{P} \text { - } \\
\text { value }\end{array}$ & HR & $95 \% \mathrm{Cl}$ & P-value \\
\hline T Stage & 1.41 & $1.04-1.91$ & 0.027 & 1.154 & \multicolumn{2}{|l|}{$\begin{array}{l}0.86- \\
1.54\end{array}$} & 0.327 & 1.808 & $1.43-2.29$ & $<0.001$ \\
\hline N Stage & 1.802 & $1.38-2.35$ & $<0.001$ & 1.64 & \multicolumn{2}{|l|}{$\begin{array}{l}1.29- \\
2.09\end{array}$} & $<0.001$ & 1.892 & $1.53-2.34$ & $<0.001$ \\
\hline Grade & 1.27 & $\begin{array}{l}0.732- \\
2.21\end{array}$ & 0.393 & 1.19 & \multicolumn{2}{|l|}{$\begin{array}{l}0.73- \\
1.94\end{array}$} & 0.487 & 1.105 & $0.706-1.730$ & 0.661 \\
\hline $\begin{array}{l}\text { Molecular } \\
\text { Type }\end{array}$ & 1.737 & $1.39-2.17$ & $<0.001$ & 1.66 & \multicolumn{2}{|l|}{$\begin{array}{l}1.36- \\
2.02\end{array}$} & $<0.001$ & 1.644 & $1.371-1.973$ & $<0.001$ \\
\hline \multicolumn{4}{|l|}{ Covariate } & & \multicolumn{2}{|r|}{ HR } & \multicolumn{2}{|c|}{$95 \% \mathrm{Cl}$} & \multicolumn{2}{|c|}{$P$ value } \\
\hline \multicolumn{3}{|c|}{ Age ( $\leq 44$ vs $>44)$} & & & \multicolumn{2}{|c|}{0.809} & \multicolumn{2}{|c|}{$0.44-1.49$} & \multicolumn{2}{|c|}{0.498} \\
\hline \multicolumn{3}{|c|}{ Menopausal Status (pre vs post) } & & & \multicolumn{2}{|c|}{0.839} & \multicolumn{2}{|c|}{$0.52-1.36$} & \multicolumn{2}{|c|}{0.477} \\
\hline \multicolumn{3}{|l|}{ T-stage } & & & \multicolumn{2}{|r|}{1.94} & \multicolumn{2}{|c|}{$1.53-2.46$} & \multicolumn{2}{|c|}{$<0.001$} \\
\hline \multicolumn{3}{|l|}{$\mathrm{N}$-stage } & & & & 2.14 & & -2.72 & $<0$ & 001 \\
\hline Tumor Grad & & & & & & 3.27 & 2.0 & $9-5.12$ & $<0$. & 001 \\
\hline Histology & & & & & & 0.838 & 0.6 & $7-1.04$ & 0.1 & \\
\hline Chemothera & & & & & & 0.69 & 0.4 & $4-1.08$ & 0.1 & \\
\hline Boost & & & & & & 1.49 & 0.9 & $4-2.35$ & $0.0 \varepsilon$ & \\
\hline Molecular S & pes & & & & & 1.836 & 1.5 & $4-2.19$ & $<0$. & 001 \\
\hline
\end{tabular}

\section{TABLE 3: Cox Regression Analysis for OS, LRFS, and DMFS}

OS: overall survival; LRFS: local recurrence-free survival; DMFS: distant metastasis-free survival; HR: hazard ratio

An increase of T Stage from 1 to 4 increases hazard rate six-fold and a change from N0 to N3 increases hazard ratio more than seven-fold. Hazard ratio (HR) increased by $40 \%$ for LB, 2.5 -fold for HER2, and close to five-fold for TN subtypes when compared to LA.

\section{Discussion}

The identification of multiple molecular subtypes of breast cancer has allowed investigators to compare clinical BC outcomes amongst these subgroups. Many studies have demonstrated different recurrence and survival rates between subtypes [7-16]. In this retrospective review, we 
analyzed the post-radiotherapy pattern of failure and clinical outcome in a cohort of 1,088 patients. As expected, the most prevalent molecular subtype was LA, which is comparable to the Korean and Brazilian cohorts previously reported [8, 10]. Of the four subtypes, the LA subtype tends to have the best prognosis, fairly high survival, and low recurrent or metastases rates. The TN and HER2 subtypes of breast cancer were associated with a significantly poorer overall survival and prone to earlier recurrence and metastases. Our results demonstrate a significant association between molecular subtype and survival. The risk of death and relapse/metastases increases fewfold in TN compared to LA. Future prospective studies are warranted and could ultimately lead to the tailoring of adjuvant radiotherapy treatment fields based on both molecular subtype and the more conventional clinicopathologic characteristics. When we investigated these four breast cancer molecular subtypes with regard to patients' age, the TN subtype tend to occur more often in younger women (<45), which is consistent with the findings of Noh and Carey who reported the triple negative and HER2 subtype were more common in the young age group of African-American and Asian patients $[9,12]$.

The failure rate in our cohort was relatively low and comparable to $13.8 \%$ reported by Zhang, et al. [14]. Of the four subtypes, LA tends to have the lowest failure rate with low rates of local recurrence and distant metastasis. This could be due to fact that LA subtypes are usually ER+ and treatment for these tumors often includes hormone therapy $[3,17]$. The TN and HER2 subtypes, on the contrary, were associated with higher rates of local recurrence and higher distant metastasis rates than LA subtypes, which is different from other studies showing that the TN and HER2 subtypes are not at significantly increased risk for local or local regional recurrence [8-9, 18-19] (Table 4). 


\section{Cureus}

\begin{tabular}{|c|c|c|c|c|c|}
\hline $\begin{array}{l}\text { Author } \\
\text { (Ref. \#) }\end{array}$ & $\begin{array}{l}\text { Publish } \\
\text { Year }\end{array}$ & $\begin{array}{l}\text { Number } \\
\text { of } \\
\text { patients }\end{array}$ & $\begin{array}{l}\text { Median } \\
\text { Follow-up } \\
\text { (Years) }\end{array}$ & Local Recurrence Rate \% & $\begin{array}{l}P \text { - } \\
\text { value }\end{array}$ \\
\hline Haffty [7] & 2006 & 482 & 7.9 & TN: 17; Non-TN: 17 & 0.823 \\
\hline Dent [18] & 2007 & 1601 & 8.1 & TN: 13; Non-TN: 12 & 0.77 \\
\hline $\begin{array}{l}\text { Freedman } \\
{[19]}\end{array}$ & 2009 & 753 & 5 & TN: 3.2; Luminal: 2.3; HER2: 4.6 & 0.36 \\
\hline $\begin{array}{l}\text { Ewan } \\
\text { Millar [20] }\end{array}$ & 2009 & 498 & 7 & TN: 17.3; LA: 5.1; LB: 8.7; HER2: 15.4 & 0.012 \\
\hline $\begin{array}{l}\text { Gabos } \\
{[21]}\end{array}$ & 2010 & 618 & 4.8 & $\begin{array}{l}\text { HER2: HR 11.13; 95\% Cl } 2.78 \text { - 44.53; TN: HR 4.72; 95\% } \\
\text { Cl } 1.53 \text { - } 14.52\end{array}$ & SS \\
\hline $\begin{array}{l}\text { Kennecke } \\
{[15]}\end{array}$ & 2010 & 2,985 & 12 & TN: 14; LA: 8; LB: 10; HER2: 21 & 0.005 \\
\hline Noh [9] & 2011 & 596 & 6.6 & Luminal: 4.1\%, TN: 7.0\%, HER2: 10.1\% & 0.151 \\
\hline $\begin{array}{l}\text { Lowery } \\
\text { [22] }\end{array}$ & 2012 & 12,592 & 4.8 & $\begin{array}{l}\text { Luminal: RR 0.34; 95\% CI } 0.26 \text { - 0.45); TN: RR 0.38; 95\% } \\
\text { CI } 0.23 \text { - 0.61); HER2: RR 1.44; 95\% Cl } 1.06 \text { - 1.95) }\end{array}$ & SS \\
\hline $\begin{array}{l}\text { Muanza } \\
{[16]}\end{array}$ & 2013 & 993 & 4.3 & LA: 1.8; LB: 7.4; HER2: 6.8; TN: 11.4 & 0.001 \\
\hline
\end{tabular}

\section{TABLE 4: Local Recurrence Difference in Molecular Subtypes}

HER2: human epidermal growth factor receptor-2; LA: luminal-A; LB: luminal-B; LR: local recurrence; SS: statistically significant; TN: triple negative; RR: recurrence rate

For luminal B, our data is consistent with that reported by Tran, et al. with regards to the higher rate of local recurrence and distant relapse to bone and lung [13]. Breast or chest wall relapse was the most frequent site of local recurrence among LA - 61.5\% (8/13), LB - 66.7\% (4/6), and HER2 - 66.7\% (2/3) groups. In contrast, regional lymph node relapse was the most common site of recurrence in $60.0 \%$ of TN cases $(9 / 15)$. Bone was the most common site of DM in LA (41.7\%), while LB and TN subtypes were most associated with lung metastasis $(57.1 \%$ and $36.7 \%$, respectively). The TN subtype was also associated with a relatively high proportion of brain metastasis at 33.3\% (9/30). However, in the HER2 group, an even higher ratio of brain metastasis (50\%) was observed and represented the most common site of DM in this group. This may be caused by trastuzumab's inability to cross the blood-brain barrier and is compatible with Gabos' report [21]. There was no statistical difference between sites of recurrence and metastasis, likely due to the relatively small number of events. However, it has been reported in other studies that LA and TN were respectively associated with bone metastasis and with visceral metastasis [19, 21]. To our knowledge, this study is the first to report that TN is associated with a higher incidence of regional lymph node recurrence. This could be of clinical significance and consideration whether to adjust radiation fields to cover regional lymph nodes is warranted, although other series have not shown a TN subtype association with higher 
regional lymph node involvement [20, 23-24]. Lowery's recent review reports that patients with TN and HER2 breast tumors are at increased risk of developing LRR following breastconserving therapy (BCT) or mastectomy [22]. Breast cancer subtypes should be taken into account when considering local control and potentially identify those at increased risk of LRR, who may benefit from a more aggressive local treatment. Another interesting finding in our series was that internal mammary lymph node involvement was also more commonly observed in the TN group - 33.3\% (3/9). It begs the question as to whether we should consider internal mammary lymph node prophylactic irradiation in the TN subtype; however, additional prospective data is still needed to support this. The MA.20 randomized clinical trial demonstrated that adjuvant regional nodal irradiation reduces locoregional and distant recurrences and improves disease-free survival (DFS) with a trend to also improve OS in highrisk lymph node negative or node positive breast cancer treated with breast-conserving surgery and adjuvant systemic therapies [25]. The secondary analysis of this randomized trial database of more than 1,800 patients based on constructed molecular subtypes could provide additional information regarding the value of regional adjuvant radiotherapy for TN breast cancer patients. Although a boost to the surgical bed did not show a benefit with regard to overall survival for TN patients, our multivariate analysis revealed a benefit in local control $(p=0.049)$, similar to the one reported by Abdulkarim, et al. [26].

We have demonstrated that the molecular subtype was the most significant factor associated with survival, with the TN subtype being the least favorable one. Braunstein, et al. reported similar results for disease-free survival in patients with locoregional recurrence after breastconserving therapy [27]. In 82 patients with local recurrence, the risk of dying increased 4.5 folds in TN compared to the Luminal A subtype. Probable explanations for increased risk in TN subtype include ineffectiveness of hormonal therapy or HER2-directed agents.

The shortcomings of our research are that this is a retrospective study. In addition, the followup period of this cohort is relatively short with a low event rate. Our ongoing follow-up with the cohort would overcome this limitation and allow an examination of the long-term implications of different molecular subtypes on the survival and the pattern of recurrence of breast cancer patients.

\section{Conclusions}

Of the four subtypes, the LA subtype tends to have the best prognosis, fairly high survival, and low recurrent or metastases rates. The TN and HER2 subtypes of breast cancer were associated with significantly poorer overall survival and were prone to earlier recurrence and metastases. Our results demonstrate a significant association between molecular subtype and survival. The risk of death and relapse/metastases increases fewfold in TN compared to LA. Future prospective studies are warranted and could ultimately lead to the tailoring of adjuvant radiotherapy treatment fields based on both the molecular subtype and the more conventional clinicopathologic characteristics.

\section{Additional Information \\ Disclosures}

Human subjects: Consent was obtained by all participants in this study. Jewish General Hospital Ethics Review Board issued approval CR1366. Animal subjects: All authors have confirmed that this study did not involve animal subjects or tissue. Conflicts of interest: In compliance with the ICMJE uniform disclosure form, all authors declare the following:

Payment/services info: All authors have declared that no financial support was received from any organization for the submitted work. Financial relationships: All authors have declared that they have no financial relationships at present or within the previous three years with any 
organizations that might have an interest in the submitted work. Other relationships: All authors have declared that there are no other relationships or activities that could appear to have influenced the submitted work.

\section{Acknowledgements}

The research was funded by a WEBC grant from the Jewish General Hospital Foundation. The authors thank Beatrice Fournier for her review of this manuscript.

\section{References}

1. Sørlie T, Perou CM, Tibshirani R, Aas T, Geisler S, Johnsen H, Hastie T, Eisen MB, van de Rijn M, Jeffrey SS, Thorsen T, Quist H, Matese JC, Brown PO, Botstein D, Lønning PE, BørresenDale AL: Gene expression patterns of breast carcinomas distinguish tumor subclasses with clinical implications. Proc Natl Acad Sci U S A. 2001, 98:10869-74. 10.1073/pnas.191367098

2. Cancer Genome Atlas Network: Comprehensive molecular portraits of human breast tumours . Nature. 2012, 490:61-70. 10.1038/nature11412

3. Perou CM, Sørlie T, Eisen MB, van de Rijn M, Jeffrey SS, Rees CA, Pollack JR, Ross DT, Johnsen H, Akslen LA, Fluge O, Pergamenschikov A, Williams C, Zhu SX, Lønning PE, Børresen-Dale AL, Brown PO, Botstein D: Molecular portraits of human breast tumours. Nature. 2000, 406:747-52. 10.1038/35021093

4. Nielsen TO, Hsu FD, Jensen K, Cheang M, Karaca G, Hu Z, Hernandez-Boussard T, Livasy C, Cowan D, Dressler L, Akslen LA, Ragaz J, Gown AM, Gilks CB, van de Rijn M, Perou CM: Immunohistochemical and clinical characterization of the basal-like subtype of invasive breast carcinoma. Clin Cancer Res. 2004, 10:5367-74. 10.1158/1078-0432.CCR-04-0220

5. Böcker W, Moll R, Poremba C, Holland R, Van Diest PJ, Dervan P, Bürger H, Wai D, Ina Diallo R, Brandt B, Herbst H, Schmidt A, Lerch MM, Buchwallow IB: Common adult stem cells in the human breast give rise to glandular and myoepithelial cell lineages: a new cell biological concept. Lab Invest. 2002, 82:737-46.

6. Nishimura R, Osako T, Okumura Y, Hayashi M, Toyozumi Y, Arima N: Ki-67 as a prognostic marker according to breast cancer subtype and a predictor of recurrence time in primary breast cancer. Exp Ther Med. 2010, 1:747-54. 10.3892/etm.2010.133

7. Haffty BG, Yang Q, Reiss M, Kearney T, Higgins SA, Weidhaas J, Harris L, Hait W, Toppmeyer D: Locoregional relapse and distant metastasis in conservatively managed triple negative early-stage breast cancer. J Clin Oncol. 2006, 24:5652-57. 10.1200/JCO.2006.06.5664

8. Park HS, Kim S, Kim K, Yoo H, Chae BJ, Bae JS, Song BJ, Jung SS: Pattern of distant recurrence according to the molecular subtypes in Korean women with breast cancer. World J Surg Oncol. 2012, 10:4. 10.1186/1477-7819-10-4

9. Noh JM, Choi DH, Huh SJ, Park W, Yang JH, Nam SJ, Im YH, Ahn JS: Patterns of recurrence after breast-conserving treatment for early stage breast cancer by molecular subtype. J Breast Cancer. 2011, 14:46-51. 10.4048/jbc.2011.14.1.46

10. Carvalho ST, Stiepcich MM, Fregnani JH, Nonogaki S, Rocha R, Soares FA: Evaluation of prognostic factors in stage IIA breast tumors and their correlation with mortality risk. Clinics (Sao Paulo). 2011, 66:607-12. 10.1590/S1807-59322011000400014

11. Nguyen PL, Taghian AG, Katz MS, Niemierko A, Abi Raad RF, Boon WL, Bellon JR, Wong JS, Smith BL, Harris JR: Breast cancer subtype approximated by estrogen receptor, progesterone receptor, and HER-2 is associated with local and distant recurrence after breast-conserving therapy. J Clin Oncol. 2008, 26:2373-78. 10.1200/JCO.2007.14.4287

12. Carey LA, Dees EC, Sawyer L, Gatti L, Moore DT, Collichio F, Ollila DW, Sartor CI, Graham ML, Perou CM: The triple negative paradox: primary tumor chemosensitivity of breast cancer subtypes. Clin Cancer Res. 2007, 13:2329-34. 10.1158/1078-0432.CCR-06-1109

13. Zhang C, Wang S, Israel HP, Yan SX, Horowitz DP, Crockford S, Gidea-Addeo D, Clifford Chao KS, Kalinsky K, Connolly EP: Higher locoregional recurrence rate for triple-negative breast cancer following neoadjuvant chemotherapy, surgery and radiotherapy. Springerplus. 2015, 4:386. 10.1186/s40064-015-1116-2

14. Tran B, Bedard PL: Luminal-B breast cancer and novel therapeutic targets. Breast Cancer Res. 2011, 13:221. 10.1186/bcr2904 
15. Kennecke H, Yerushalmi R, Woods R, Cheang MC, Voduc D, Speers CH, Nielsen TO, Gelmon K: Metastatic behavior of breast cancer subtypes . J Clin Oncol. 2010, 28:3271-77. 10.1200/JCO.2009.25.9820

16. Muanza TM, Wu X, Kasymjanova , Zhang S, Fan R, Mekouar H, Sultanem K: Does the Breast Cancer Molecular Subtype Affect the Post-Radiation Therapy Pattern of Recurrence?. International Journal of Radiation Oncology Biology Physics. 2013, 87:S218.

http://dx.doi.org/10.1016/j.ijrobp.2013.06.564

17. Dent R, Trudeau M, Pritchard KI, Hanna WM, Kahn HK, Sawka CA, Lickley LA, Rawlinson E, Sun P, Narod SA: Triple-negative breast cancer: clinical features and patterns of recurrence . Clin Cancer Res. 2007, 13:4429-34. 10.1158/1078-0432.CCR-06-3045

18. van 't Veer LJ, Dai H, van de Vijver MJ, He YD, Hart AA, Mao M, Peterse HL, van der Kooy K, Marton MJ, Witteveen AT, Schreiber GJ, Kerkhoven RM, Roberts C, Linsley PS, Bernards R, Friend SH: Gene expression profiling predicts clinical outcome of breast cancer . Nature. 2002, 415:530-36. 10.1038/415530a

19. Freedman GM, Anderson PR, Li T, Nicolaou N: Locoregional recurrence of triple-negative breast cancer after breast-conserving surgery and radiation. Cancer. 2009, 115:946-51. 10.1002/cncr.24094

20. Millar EK, Graham PH, O'Toole SA, McNeil CM, Browne L, Morey AL, Eggleton S, Beretov J, Theocharous C, Capp A, Nasser E, Kearsley JH, Delaney G, Papadatos G, Fox C, Sutherland RL: Prediction of local recurrence, distant metastases, and death after breast-conserving therapy in early-stage invasive breast cancer using a five-biomarker panel. J Clin Oncol. 2009, 27:4701-8. 10.1200/JCO.2008.21.7075

21. Gabos Z, Sinha R, Hanson J, Chauhan N, Hugh J, Mackey JR, Abdulkarim B: Prognostic significance of human epidermal growth factor receptor positivity for the development of brain metastasis after newly diagnosed breast cancer. J Clin Oncol. 2006, 24:5658-63. 10.1200/JCO.2006.07.0250

22. Lowery AJ, Kell MR, Glynn RW, Kerin MJ, Sweeney KJ: Locoregional recurrence after breast cancer surgery: a systematic review by receptor phenotype. Breast Cancer Res Treat. 2012, 133:831-41. 10.1007/s10549-011-1891-6

23. Crabb SJ, Cheang MC, Leung S, Immonen T, Nielsen TO, Huntsman DD, Bajdik CD, Chia SK: Basal breast cancer molecular subtype predicts for lower incidence of axillary lymph node metastases in primary breast cancer. Clin Breast Cancer. 2008, 8:249-56. 10.3816/CBC.2008.n.028

24. Billar JA, Dueck AC, Stucky CC, Gray RJ, Wasif N, Northfelt DW, McCullough AE, Pockaj BA: Triple-negative breast cancers: unique clinical presentations and outcomes. Ann Surg Oncol. 2010, 17:384-90. 10.1245/s10434-010-1260-4

25. Whelan TJ, Olivotto IA, Parulekar WR, Ackerman I, Chua BH, Nabid A, Vallis KA, White JR, Rousseau P, Fortin A, Pierce LJ, Manchul L, Chafe S, Nolan MC, Craighead P, Bowen J, McCready DR, Pritchard KI, Gelmon K, Murray Y, Chapman JA, Chen BE, Levine MN; MA.20 Study Investigators: Regional nodal irradiation in early-stage breast cancer . N Engl J Med . 2015, 373:307-16 . 10.1056/NEJMoa1415340

26. Abdulkarim BS, Cuartero J, Hanson J, Deschênes J, Lesniak D, Sabri S: Increased risk of locoregional recurrence for women with T1-2N0 triple-negative breast cancer treated with modified radical mastectomy without adjuvant radiation therapy compared with breastconserving therapy. J Clin Oncol. 2011, 29:2852-58. 10.1200/JCO.2010.33.4714

27. Braunstein LZ, Niemierko A, Shenouda MN, Truong L, Sadek BT, Abi Raad R, Wong JS, Punglia RS, Taghian AG, Bellon JR: Outcome following local-regional recurrence in women with earlystage breast cancer: impact of biologic subtype. Breast J. 2015, 21:161-67. 10.1111/tbj.12371 